\title{
Corrigendum: Surgical management of palatal teratoma (epignathus) with the use of virtual reconstruction and 3D models: a case report and literature review
}

Cynthia Minerva Gonzalez-Cantu ${ }^{1}$, Pablo Juan Moreno-Peña ${ }^{2}$, Mayela Guadalupe Salazar-Lara ${ }^{2}$, Pablo Patricio Flores García ${ }^{2}$, Fernando Félix Montes-Tapia ${ }^{3}$, Victor Hugo Cervantes-Kardasch ${ }^{4}$, Yanko Castro-Govea ${ }^{1}$

${ }^{1}$ Plastic, Aesthetic and Reconstructive Surgery Service, University Hospital "Dr. José Eleuterio González", Faculty of Medicine, Autonomous University of Nuevo Leon, Monterrey; ${ }^{2}$ Faculty of Medicine, Autonomous University of Nuevo Leon, Monterrey; ${ }^{3}$ Pediatric Surgery Service, University Hospital "Dr. José Eleuterio González", Faculty of Medicine, Autonomous University of Nuevo Leon, Monterrey; ${ }^{4}$ Laboratory of Tissue Engineering, Faculty of Medicine, University of Colima, Colima, Mexico

Arch Plast Surg 2021;48:518-523

https://doi.org/10.5999/aps.2021.00318

In the version of this article initially published, the second author's name was stated as "Pablo Juan Moreno-Peña." The correct name is "Pablo José Moreno-Peña" 